\title{
Knowledge relations and epistemic infrastructures as mediators of teachers' collective autonomy
}

\author{
Hege Hermansen
}

\begin{abstract}
This paper examines how teachers' knowledge relations and the profession's epistemic infrastructure shape collective autonomy. Professionals' autonomy derives partially from their responsibility for a specific knowledge base. This responsibility is currently challenged by educational policies and complex knowledge landscapes. Existing research has shown how epistemic policy instruments impact teachers' autonomy. However, less attention has been paid to how professional autonomy is informed by teachers' knowledge relations, and to collective, rather than individual, aspects of teachers' autonomy. Implications include how teachers can define the role of knowledge resources in professional work, and how the profession can navigate epistemic and political landscapes.
\end{abstract}

Keywords: knowledge cultures; knowledge practices; professional autonomy; professional knowledge; teachers' knowledge base 


\section{Introduction}

Historically, a source of legitimacy for professionals has been their relationship to a given knowledge base (Abbott, 1988). Trust is granted professionals partly because they keep up to date with their field of expertise and safeguard the foundation for professional work. From this perspective, the ability to define which knowledge resources should inform everyday work and how can be seen as a key source of professional autonomy.

In the teaching profession, autonomy over professional knowledge is currently being challenged. First, educational policies are increasingly employing forms of knowledge as policy instruments. Examples include the introduction of teacher standards (Bathmaker, 2000; Ceulemans, Simons \& Struyf, 2012; Evans, 2011; Sachs, 2003), expectations of research-based practice (Hargreaves, 1996; Slavin, 2007) and systematic data use (Coburn \& Turner, 2012). This policy orientation towards the epistemic dimensions of professional practices can be seen as attempts to define what forms of knowledge should be valued within the profession and how processes of work should be legitimately accounted for (Beck, 2008, 2009; Mausethagen, 2013). This orientation also represents an effort by policy makers to shape how a profession's knowledge base is developed.

A second challenge pertains to the characteristics of knowledge in contemporary societies. Present-day knowledge landscapes are complex and rapidly evolving. These landscapes involve multiple knowledge producers, including researchers, knowledge clearinghouses, educational consultants and practitioner-based networks. These actors generate knowledge resources from varied epistemological and methodological positions, and assessing their implications for practice can be a demanding task. Further, policy borrowing and digitalisation mean that teachers are often introduced to educational resources that were developed in contexts different to their own. As a consequence, significant analytical work is required to interpret the meaning potential of these resources and adapt them for use in local 
settings (Coburn, 2006; Author, 2014; Nerland \& Jensen, 2010; Spicer, 2011). This broader context makes the development and safeguarding of professional knowledge a complex endeavour and also reshapes the responsibilities associated with such work.

The term professional autonomy has multifaceted associations, including moral and ethical principles, accountability, a professional knowledge base and the capacity to justify decisions (Cribb \& Gewirtz, 2007; Mausethagen \& Mølstad, 2015, Wermke \& Höstfält, 2014). Professional autonomy can be understood in both individual and collective terms (Mausethagen \& Møldstad, 2015). Whereas the individual dimension typically refers to a professional's degree of control over everyday work, the collective dimension includes the capacity of teachers as a group to shape the structural factors that inform their work, such as the characteristics of their knowledge base, the ways in which professional work is governed, and content and design of teacher education programs. Historically, notions of individual autonomy have been strong in the teaching profession (Clement \& Vandenberghe, 2000; Little, 1990; Lortie, 2002 [1975]). In many countries, teachers have enjoyed relative freedom in deciding which knowledge resources should inform their work and how, based on a historical division of labour between the profession and the state (Hopmann, 2007). However, the developments outlined above challenge traditional notions of individual autonomy. For example, recent policy developments emphasise shared standards and (more or less) prescribed approaches to professional practice that frequently have been developed by others than teachers themselves. These policies are typically coupled with forms of governance that emphasise output controls, which hold teachers accountable for their work in historically new ways (Day, 2002; Kleinhenz \& Ingvarson, 2004). These attempts at introducing collective standards "from above" (Evetts, 2003) may impact teachers' sense of professionalism as well as the broader purposes of schooling, a topic which has been extensively covered in existing research (e.g. Biesta, 2004; Beck, 2009, 2010; Evetts, 2009). 
At the same time, contemporary knowledge landscapes demand complex epistemic engagement that would be unreasonable to designate as a purely individual responsibility. From this perspective, more collective approaches to the safeguarding of a shared knowledge base may have the potential to strengthen teachers as a collective expert community. This does not imply a 'standards based' approach where certain instructional approaches are collectively prescribed. Rather, collective approaches to the development and safeguarding of knowledge may include more systematic differentiation and specialisation within the profession, collectively shared processes aimed at identifying and evaluating relevant knowledge resources, or the development of translation mechanisms for analysing and recontextualising findings from research (Nerland, 2012; Jensen, Lahn \& Nerland, 2012b). Such approaches may also better position teachers to publicly justify and account for educational practices and their epistemic foundations, thereby strengthening teachers as political actors.

In summary, the notion of collective autonomy can appear both as a threat and a promise. In either case, professional autonomy is realised in part by the characteristics of the profession's knowledge relations. Against this background, this article discusses opportunities and challenges for collective autonomy as they emerge from teachers' approaches to professional knowledge, and the ways in which this engagement is mediated by epistemic infrastructures. Teachers' interactions with knowledge resources are interesting as a unit of analysis because they can be understood as processes where professional knowledge is defined and developed, and where the characteristics of instructional practices are shaped. These processes of knowledge work also shed light on who decides what forms of knowledge should inform educational practices and how. From this perspective, teachers' knowledge relations can be seen as one factor contributing to how the profession's autonomy is constructed and maintained. 
The main purpose of the paper is to illustrate how the characteristics of teachers' knowledge relations have consequences for a profession's collective autonomy and how different approaches to knowledge can expand or restrict teachers' abilities to define their professional practices. The argument is substantiated by three empirical representations of how teachers' knowledge practices and epistemic infrastructures can shape their professional autonomy. The next section outlines theoretical assumptions and analytical tools for examining teachers' knowledge relations. These perspectives are then applied to three different levels of analysis: the collective knowledge cultures of professions, knowledge relations in the context of school based development initiatives, and teachers' micro interactions with knowledge resources. The article ends by discussing implications for the understanding of teachers' autonomy in contemporary educational contexts.

\section{Tracing teachers' interactions with knowledge: analytical perspectives}

A point of departure for the analysis is that professional work is characterised by a connection to a specific knowledge base, which allows for a certain degree of autonomy and professional discretion in how professional practice is carried out (Abbott, 1988;

Mausethagen \& Smeby, 2016). The paper further employs analytical resources from cultural historical theory (Cole, 1996; Vygotsky, 1978; Wertsch, 1991) and social practice-based approaches to knowledge (Gherardi, 2009; Miettinen, Samra-Fredericks \& Yanow, 2009; Knorr Cetina, 1999, 2001). A key assumption within these perspectives is that human actions are constitutive of social order. Through micro-processes of routine actions, practices are sustained as expected behaviours, and everyday activities are reproduced. However, routine actions are never fully stable, and cultural tools can also be drawn on to change established conventions. Practices are renewed when their taken-for-granted aspects are scrutinised and established performances are carried out in new ways. The point of departure for examining the relationship between knowledge and autonomy is, therefore, to trace how teachers relate 
to different knowledge resources, how they create relationships between these resources and purposes of schooling, and how established practices shape (or are re-shaped by) these processes. This assumption further implies that the term 'practices' is a structural concept which does not simply refer to 'something teachers do', but to the institutionalised characteristics of their work.

A second assumption is that our relationship to the world is mediated by cultural tools (Vygotsky, 1978; Wertsch, 1991), understood as the conceptual and material artefacts that human beings use to interact with their surroundings. Artefacts are simultaneously material and ideal; in addition to their physical attributes, they are imbued with socially and historically constructed meaning potentials (Cole, 1996). When artefacts enter into dynamic relationships with each other and with human interactions, they provide direction for human action but may also have their characteristics redefined. Knowledge resources are here understood as artefacts that provide certain constraints and affordances for teachers' work. When knowledge resources are introduced to schools, they come imbued with meaning potentials that direct, but do not determine, teachers' activities. For new knowledge resources to become an integrated part of everyday work, their meaning potentials need to be worked upon and adapted to local contexts. From this perspective, another analytical point of departure is to trace how teachers explore the meaning potential of different knowledge resources, how these resources are developed and stabilised and how they sustain or challenge institutional structures and purposes (Author, 2015a; Nerland \& Jensen, 2012)

Tracing these dynamics provides insight into the relationship between teachers' orientations towards knowledge resources and their implications for instructional development (Author, 2015a). For example, if the meaning potential of a knowledge resource is not sufficiently opened up for exploration, teachers may adopt a confined and restricted approach to new forms of knowledge, with limited implications for existing practices. 
Conversely, if the knowledge resource is not sufficiently stabilised, its potential as an agentic tool in educational practices will be limited. Finally, if knowledge resources are not sufficiently recontextualised (Guile, 2010; Linell, 1998) to align with educational purposes and the specific social and historical context of a given school setting, they may not fulfil their role in supporting student learning (e.g. Marshall \& Drummond, 2006).

A third assumption is that a given field of expertise (such as the teaching profession) is characterised by a distinct knowledge culture (Knorr Cetina, 1999; Nerland, 2012), understood as particular conventions for approaching, developing and safeguarding knowledge. Such knowledge practices include processes of accessing and recontextualising new knowledge, knowledge production and verification; and the distribution and accumulation of knowledge (Nerland, 2008). These processes can be analysed along different dimensions. For example, a profession may, to a greater or lesser extent, be oriented towards research-based or experience-based knowledge, formal or informal means of knowledge sharing or hierarchical or horizontal knowledge accumulation. The question of what is considered 'knowledge' in professional work is here approached empirically, since practitioners' work with knowledge depends on historically formed practices and their institutional values and purposes (Edwards \& Daniels, 2012). By examining how these knowledge practices are enacted, identifying the knowledge cultures of a professional field and their implications for professional learning and knowledge development becomes possible (Jensen, Lahn, \& Nerland, 2012b). In school settings, teachers' knowledge relations are further mediated by organisational roles, routines and resources (Gherardi, 2000, 2006; Nicolini, Yanow \& Gherardi, 2003). These conventions can shape how teachers seek out knowledge as part of everyday work, how knowledge is shared and recontextualised within a workplace and whether knowledge development is carried out as an individual or a collective pursuit (Author, 2015b). 
Key questions of analytical interest are how these mediating tools shape teachers' knowledge relations and what the implications are for efforts aimed at developing institutional practices and the profession's knowledge base. These mediating tools can be understood as components of a profession's epistemic infrastructure. An epistemic infrastructure is considered profession specific when it is tailored to support professional practice. For example, as part of lesson planning, a history teacher may use digital resources that are tailored to a particular learning objective about the Second World War in given a national curriculum (a profession specific resource). In contrast, she may also browse the internet for information about the Second World War on web sites that are not specifically aimed at teachers or educational activities (a non-profession specific resource). Without an epistemic infrastructure that caters to the profession's particular needs, teachers will be left to do a significant amount of assessment and recontextualisation of knowledge resources on an individual basis. Such support mechanisms do not merely point to the availability of relevant classroom resources, but to the extent to which schools, and the profession more broadly, provide and sustain broader systems for accessing, circulating, developing and critically assessing knowledge. Infrastructure for recontexualising knowledge also indicates whether a profession has institutionalised strategies for assessing knowledge resources emerging from outside of the professional community, and how the relevance and quality of such resources are established. Without such support mechanisms, the capacity to deal with pluralistic and extensive knowledge landscapes, as well as recurrent educational reforms, may be weakened. From this perspective, a profession-specific epistemic infrastructure can be seen as a necessary prerequisite for the systematic development and safeguarding of a profession's knowledge base. 


\section{Knowledge relations, epistemic infrastructures and collective autonomy: empirical examples}

In this section, I outline three empirical examples that each demonstrate how collective autonomy is mediated by teachers' engagement with knowledge resources. The examples are taken from already published research. The first section examines relationships between knowledge and autonomy from the perspective of professional groups as collectives and is based on a research project that compared knowledge cultures in four different professions (Jensen et al., 2012a; Nerland \& Karseth, 2013, 2014). The purpose of this section is to show how teachers' knowledge relations, and the epistemic infrastructure that mediates these relations, can shape a profession's opportunities for developing and safeguarding their knowledge base. The second section examines how knowledge practices and epistemic infrastructures at the school level can mediate teachers' knowledge relations in ways that expand or limit their collective autonomy when faced with expectations of instructional change. The final section explores how the micro-processes (Little, 2012) of teachers' interactions with knowledge resources may direct the role these resources play in instructional activities, as exemplified through teachers' work with assessment criteria. The purpose of this section is to illustrate how these micro-processes, and the institutional purposes that shape them, can expand or restrict teachers' opportunities for defining the characteristics of particular knowledge resources. In line with practice based approaches, these micro-processes also represent an analytical entry point for studying institutional practices.

\subsection{Professional knowledge cultures and collective autonomy}

In this section, I contrast the knowledge cultures and epistemic infrastructures of Norwegian teachers and nurses. Although the main focus in this paper is the teaching 
profession, a comparative perspective is useful to highlight salient characteristics of teachers' knowledge cultures. In the Norwegian context, these two professions have similarities that make them reasonable to compare, such as their historical trajectories of development from practice-based training programs to their current constitution as bachelor degree programs at university colleges and their traditional emphasis on human relations as a cornerstone of their work. The discussion below contrasts the professions' respective knowledge practices and epistemic infrastructures, as identified through quantitative surveys, qualitative interviews, participant logs and document analyses. The purpose of the comparison is not to statistically generalise the empirical findings, but to analytically account for how collective autonomy is mediated by teachers' engagement with knowledge resources.

Jensen et al. (2012) report that the nurses are supported by a range of knowledge resources specifically designed to support professional practice. This infrastructure centres on collectively shared procedures and is linked to broader knowledge landscapes such as scientific communities and regulatory bodies. Combined with access to specialists and institutionalised collegial supervision, professional learning and knowledge development are an integrated aspect of everyday work. By contrast, the teachers reported that they lack a shared, profession-specific epistemic infrastructure. Klette and Carlsten (2012) state that "when asked how they access different kinds of organised theoretical and experience-based knowledge resources, our novice teachers agree that they are in a constant struggle against an almost non-existent support structure" (p. 80), and the teachers appeared to lack a systematic overview of available knowledge resources. As a consequence, it becomes challenging for the teachers to identify relevant knowledge to address problems of practice (Jensen et al., 2012). A related characteristic is that the teachers' knowledge cultures are only loosely connected to broader knowledge landscapes, a finding which is also reported in much international research (Bakkenes, Vermunt, \& Wubbels, 2010; Lohman \& Woolf, 2001; 
Meirink, Meijer, Verloop \& Bergen, 2009; Pedder \& Opfer, 2013; Richter, Kunter,

Klusmann, Lüdtke, \& Baumert, 2011). Knowledge sharing and development tend to be local in character, where the focal point for knowledge production and development is within the different communities in each school.

These differences are reflected in research on the respective professional organisations. Nerland and Karseth $(2013,2014)$ describe how the Norwegian Nurses Organisation (NNO) has identified the development of nursing science and the organisation of shared knowledge resources as key priorities. Emphasis on a scientific knowledge base for nursing has been a main principle underlying this approach, although it is coupled with a recognition of experience-based knowledge and the relational characteristics of nurses' work. A key strategy has been to affirm the significance of shared standards that can be promoted as research based and aligned with what the organisation perceives as "best practices".

In contrast, the Union of Education Norway (UoE) has a long history of emphasising the importance of individual discretion and 'methodological freedom' (metodefrihet), partially as a response to attempts by policy makers to externally regulate the profession. The UoE has also emphasised knowledge development from below by explicating the practicebased knowledge and reflections of individual teachers and making them available for broader circulation. At the same time, the union has been paying increased attention to research, visible in its strategy documents and through its recently launched portal on educational research (utdanningsforskning.no). According to Nerland and Karseth (2013), the designation of knowledge development as an individual responsibility is pronounced within the UoE compared with the NNO.

In terms of recontextualising knowledge, Jensen et al. (2012b) report that the nurses have knowledge resources that "are locally adapted and appear to have strong 'translation mechanisms' that mediate between globalised, abstract knowledge and the local realities of 
the hospital wards" (p. 17). For example, specially assigned nurses are responsible for keeping up to date with certain areas of research and initiating the development and adaptation of local practices when necessary (Jensen \& Christiansen, 2012). More generally, they report a range of knowledge resources that support the recontextualisation of knowledge, including manuals, an intranet, reference works and textbooks (Jensen et al., 2012b). Teachers, however, report that they, to a great extent, experiment individually with knowledge resources combined with informal discussions with colleagues. Several informants expressed that they lack organisational infrastructure or support from the school leadership, and they find it difficult to identify standards systematically shared among their colleagues. A general finding is that "there are no routines, nor any formal infrastructures for knowledge distribution at the school level to serve as bridges" between knowledge circulating outside of the school and everyday practice (Klette \& Carlsten, 2012, p. 81). Although the teachers express a strong desire to learn, Klette and Carlsten (2012) conclude that the combination of having to engage with a vast, complex and unsystematised field of knowledge and the lack of support structures for knowledge translation can negatively impact professional learning.

This brief empirical comparison depicts a more general principle: that the organisation of knowledge resources within a professional field, combined with established conventions for approaching knowledge, create specific constraints and affordances for developing and safeguarding a professional knowledge base. In the Norwegian case, an implication of the lack of a collectively shared knowledge infrastructure is that the main responsibility for seeking out, assessing and recontextualising new knowledge resources is left to individual teachers. In complex knowledge landscapes, this responsibility may become a rather strenuous task and may also lead to much duplication of work. The framing of knowledge development as an individual responsibility may also constrain teacher 
collaboration, as teachers will to a lesser extent have a shared epistemic basis for instructional development.

A strong emphasis on knowledge work as an individual responsibility, combined with the absence of a shared knowledge base, may also leave teachers vulnerable in settings where knowledge is contested and associated with competing political agendas. The political introduction of standards based reforms have in several cases taken place in environments where the teaching profession have historically had weak collective infrastructures for safeguarding knowledge. In such contexts, the lack of a shared, epistemic infrastructure developed "from within" means that teachers have few collective tools to counter attempts at professionalisation "from above" (Evetts, 2003). From this perspective, profession specific epistemic infrastructures may strengthen teachers as political actors, in addition to supporting their everyday work.

\subsection{Knowledge relations and collective autonomy at the school level}

This section addresses how teachers' knowledge relations in school settings are mediated by organisational roles and routines, with consequences for teachers' opportunities to define instructional development. The study drawn upon (Author, 2015b) contrasted two groups of teachers at two lower secondary schools that took part in an Assessment for Learning (AfL) project led by the local education authorities. All project schools had established so-called AfL groups tasked with supporting the development of formative assessment practices at the school level. The study examined how the two groups approached knowledge resources in distinctly different ways, which, in turn, had consequences for their opportunities to shape practice development at their respective schools (termed Weston and Bridges). 
The AfL group at Weston spoke of taking on significant responsibility and formal authority to introduce formative assessment practices at the school. They used a range of organisational routines and material resources to introduce and share assessment resources with their colleagues, including a digital platform, weekly teacher team meetings, shared templates used for lesson preparation, scholarly publications and meetings for all teaching staff. Established routines were in place for circulating new knowledge resources, and specific arenas were designated as spaces where the teachers would work on recontextualising newly introduced resources. These moves were coupled with a strategy aimed at developing shared standards for assessment practices at the school, and the AfL group emphasised the collective responsibility of all the school's teachers to make formative assessment part of their everyday practices. The AfL group oriented their work towards the school level, as they attempted to create shared organisational routines and resources to support what they termed the 'institutionalisation' of formative assessment practices.

At Bridges, the AfL group did not position themselves as decision makers with any formal authority, but rather as a 'think tank' for the school leadership. They emphasised their role as 'translators' between, on the one hand, the local education authorities and school leadership and, on the other hand, the teachers at the school. This group primarily introduced and shared knowledge through informal, face-to-face encounters and assisted their colleagues with the recontextualisation of AfL resources. These interactions typically emerged spontaneously as part of everyday work. The AfL group placed little emphasis on shared organisational routines and material resources across the school, considering this the responsibility of the school leadership. Instead, their work was oriented towards supporting the individual work of their colleagues. The AfL group also clearly emphasised their colleagues' individual autonomy and, in contrast to the group at Weston, did not consider it their role to advocate or support the standardisation of assessment practices. 
Preprint version of article published in Teaching and Teacher Education: An International Journal of Research and Studies. 65, 1-9. doi:10.1016/j.tate.2017.03.003. There may be minor differences between this manuscript and the published version.

Table 1: Key dimensions of the AfL groups' epistemic and organisational practices

\begin{tabular}{|c|c|}
\hline AfL group at Weston & AfL group at Bridges \\
\hline $\begin{array}{l}\text { Mandate and role within the organisation: } \\
\text { Formal authority and responsibility to } \\
\text { introduce AfL at the school and hold teachers } \\
\text { and the school leadership accountable for } \\
\text { their engagement with AfL. }\end{array}$ & $\begin{array}{l}\text { Mandate and role within the organisation: } \\
\text { Formal role to act as a 'think tank' for the } \\
\text { leadership; no formal role towards } \\
\text { colleagues, but informal role as knowledge } \\
\text { translators and adaptors. }\end{array}$ \\
\hline $\begin{array}{l}\text { Knowledge introduced and shared through a } \\
\text { range of organisational routines and material } \\
\text { resources, aimed at systematic circulation of } \\
\text { AfL resources across the school. }\end{array}$ & $\begin{array}{l}\text { Knowledge introduced and shared through } \\
\text { informal, face-to-face encounters, typically in } \\
\text { the context of teacher team meetings and as } \\
\text { part of everyday work. }\end{array}$ \\
\hline $\begin{array}{l}\text { Knowledge development and adaptation: The } \\
\text { group requested teachers across the school to } \\
\text { systematically experiment with AfL-related } \\
\text { principles and methods. }\end{array}$ & $\begin{array}{l}\text { Knowledge development and adaptation: The } \\
\text { group worked informally with colleagues to } \\
\text { adapt AfL-related ideas and resources, based } \\
\text { on emerging and subject-specific needs. }\end{array}$ \\
\hline $\begin{array}{l}\text { New knowledge sought out through a range of } \\
\text { different avenues, with written knowledge } \\
\text { sources and research designated important } \\
\text { roles. }\end{array}$ & $\begin{array}{l}\text { New knowledge sought out primarily through } \\
\text { face-to-face interactions with other teachers, } \\
\text { accompanied by the exchange of specific } \\
\text { tools and methods. }\end{array}$ \\
\hline $\begin{array}{l}\text { Emphasised the collective responsibility of } \\
\text { teachers to standardise AfL practices at the } \\
\text { school and integrate formative assessment } \\
\text { into organisational routines. }\end{array}$ & $\begin{array}{l}\text { Emphasised the individual autonomy of the } \\
\text { teachers at the school; however, the group } \\
\text { indirectly supported the leadership's efforts } \\
\text { to standardise assessment practices. }\end{array}$ \\
\hline $\begin{array}{l}\text { Their talk oriented towards collective } \\
\text { development at the school level and school- } \\
\text { wide conventions for conducting formative } \\
\text { assessment. }\end{array}$ & $\begin{array}{l}\text { Their talk oriented towards the individual } \\
\text { practices of teachers in the AfL group and the } \\
\text { practices of their respective teacher teams. }\end{array}$ \\
\hline
\end{tabular}

The different characteristics of the groups' knowledge relations had implications for how knowledge resources could be employed towards instructional development at the school level. One implication concerns how the teaching staff as a collective could make use of new resources. The different approaches to introducing and sharing knowledge had consequences for who were able to access new assessment resources and when and how they were able to do so. At Weston, resources circulated fairly systematically across the school through a range of organisational routines and material resources, whereas access to assessment resources at Bridges was, to a great extent, mediated through informal and 
personal interactions. As a result, the teaching staff at the two schools were differently positioned in terms of how they could access both the new assessment resources and the support to recontextualise them. In summary, they had quite different epistemic support structures when faced with expectations of instructional change.

The differences in knowledge relations also influenced how the AfL groups were able to inform the direction of instructional development. Although the AfL group at Bridges insisted on the importance of individual autonomy for the teaching staff, the way in which the group's work was positioned meant that key decisions were ultimately taken by the school leadership. In contrast, the AfL group at Weston was given authority to direct the development of assessment practices, including those of the leadership group. A premise for the development work at Weston was that the teachers, as a collective, needed to arrive at a shared set of AfL practices. Individual autonomy was downplayed and replaced by a process that aimed to systematically incorporate different views and experiences with AfL resources with the explicit purpose of arriving at collectively held standards. This finding suggests that approaches to knowledge work aimed at preserving egalitarian forms of work and individual autonomy may, in the long term, weaken teachers' influence over practice development at the school level. Although the individual autonomy of the teachers at Weston was curtailed, as a collective, they arguably had greater influence over how formative assessment practices at the school were developed than the teachers at Bridges had.

More generally, these two cases underscore that specific combinations of knowledge relations and organisational roles and routines can constitute teachers' collective autonomy at the school level in quite different ways. It is important to emphasise that the two groups' knowledge relations should not be understood merely as properties of the groups themselves, or their individual members. Rather, the groups' work must be interpreted in the context of the institutional practices that inform local knowledge relations and epistemic infrastructures. 
Preprint version of article published in Teaching and Teacher Education: An International Journal of Research and Studies. 65, 1-9. doi:10.1016/j.tate.2017.03.003. There may be minor differences between this manuscript and the published version.

Other important mediating factors are prevailing notions of teacher autonomy and conventions for addressing expectations of instructional change. This underscores the role of school leaders in fostering school based knowledge cultures that support collective forms of learning and knowledge development, and ensuring that teachers have access to organisational roles and routines that facilitate the construction of an epistemic infrastructure "from within" (Evetts, 2003).

\subsection{The micro dynamics of teachers' knowledge relations: the case of assessment criteria}

The final case addresses the micro-processes (Little, 2012) of teachers' interactions with knowledge resources. The characteristics of teachers' interactions with knowledge resources is of analytical interest because the ways in which knowledge resources are explored, stabilised and invested with institutional purposes have implications for teachers' capacities to define their role in instructional activities. A finding in much educational research is that how instructional practices develop depends not only on what kinds of resources are introduced to schools, but how they are taken up, developed and enacted by teachers (e.g. Coburn, 2006; Edwards, 2008; Horn \& Little, 2010; Hutchinson \& Hayward, 2005). Of particular interest here is the role that these interactional processes play in connecting specific knowledge resources to the institutional purposes at play in education. More generally, such micro-processes represent an analytical entry point for studying how broader knowledge cultures are constituted, in line with the theoretical assumption that human actions are constitutive of institutional practices. An interesting case for exploring such dynamics is that of assessment criteria. The international turn towards output-based curricula, formative assessment (Black \& Wiliam, 1998; Hopfenbeck, Throndsen, Lie \& Dale, 2012) and high stakes tests (Stobart \& Eggen, 2012; Valli \& Buese, 2007) means that teachers are generally expected to systematically use assessment criteria as part of everyday work. Assessment 
Preprint version of article published in Teaching and Teacher Education: An International Journal of Research and Studies. 65, 1-9. doi:10.1016/j.tate.2017.03.003. There may be minor differences between this manuscript and the published version.

criteria are complex artefacts that shape educational activities, but also require interpretation and meaning making (Wyatt-Smith \& Klenowski 2013; Sadler, 2007). Previous research has shown that how assessment criteria are approached has consequences for how instructional activities are performed and how the criteria are connected to broader purposes of schooling (Hay \& Macdonald, 2008; Torrance, 2007; Van der Schaaf, Baartman, \& Prins, 2011). For example, Torrance's (2007) study illustrates a use of assessment criteria where the emphasis is on 'getting students through' to obtain formal qualifications, and where learning is equated with 'criteria compliance'. He describes how the criteria themselves, rather than the broader learning objectives they are supposed to point towards, are made into the institutional purpose for instructional activities. Combined with a detailed level of 'coaching' of students towards the standards specified by the assessment criteria, a "transparency that promotes instrumentalism" (p. 290) is developed which makes the assessment criteria appear as educational objectives in and of themselves.

Torrance's study highlights the importance of how teachers interact with assessment resources. In previous work (Author \& Co-Author, 2014; Author, 2014), I have illustrated how teachers mobilise varied forms of knowledge to mediate the development of assessment criteria, including subject knowledge, didactical and pedagogical knowledge, national and local curricula, and knowledge about specific student groups. Through processes of exploration and specification, teachers gradually assigned more specific meanings to assessment criteria and stabilised their role and purpose for the task at hand. They also considered how the assessment criteria defined the division of labour between teachers and students, discussed how to formulate and communicate the assessment criteria to students and imagined the assessment criteria in use. A brief example of how these micro-processes of recontextualisation inform how assessment criteria are connected to broader purposes of schooling is depicted in the extract below, taken from a teacher team conversation (Author \& 
Co-Author, 2014, p. 199). The teachers had recently been approached by colleagues outside of the team, who complained that the use of assessment criteria was restricting their students' learning. This complaint triggered a discussion of how assessment criteria can be recontextualised in ways that offer students more restrictive or expansive ways of learning.

Table 2: Data extract

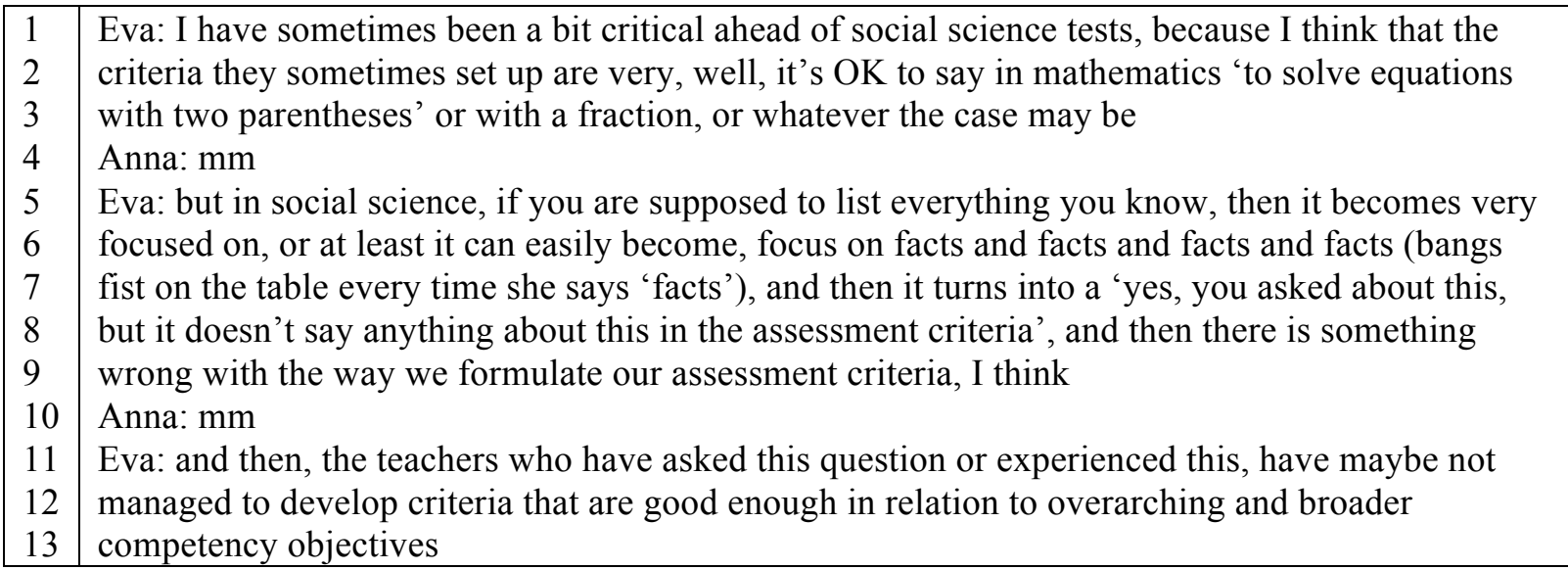

Eva's account illustrates the importance of how mediating tools (in this case, the subject knowledge) are used when knowledge resources (in this case, assessment criteria) are explored and stabilised. It also points to the importance of how knowledge resources, during their recontextualisation processes, are connected to broader purposes of schooling. More specifically, Eva questions whether these teachers have managed to create connections between the assessment criteria they produced and the competency objectives of the national curriculum, and argues that this can have important implications for whether the criteria support or restrict students' learning. Finally, the extract illustrates that recontextualisation processes have implications for how relations between students and teachers are constituted and what students and teachers are able to hold each other accountable for. Eva suggests that the students' attempts to negotiate their grades based on the formulation of assessment criteria are directly related to how the assessment criteria have been developed. 
The extract highlights some of the ways in which the micro-processes of teachers' interactions with knowledge resources can inform how the characteristics of these resources are (re-)shaped, and how they are connected to purposes of schooling. In turn, this may position these knowledge resources as more or less supportive of students' learning. How these interactions emerge can be understood as a dialectic between the specific ways in which teachers approach knowledge resources, and the institutional demands that shape these processes. Teachers' work contexts today are characterised by a variety of institutional demands that are often perceived to be in tension with each other. One example is national tests and the use of student results to develop instructional activities, which simultaneously represent expectations of school development and accountability, of supporting student learning and improving test scores (Klenowski \& Wyatt-Smith, 2012; Mausethagen, 2013; Stobart \& Eggen, 2012). Another example is expectations of research based practice. Depending on how research literature is approached and framed within the broader context of schooling, teachers may approach research findings as prepackaged 'scripts' based on "what works" or as knowledge resources than can be subjected to interpretation and recontextualisation (cf. e.g. Biesta, 2007). Here, processes of elaboration and stabilisation are important as they inform at which level of specificity knowledge resources inform instructional activities, as the example of assessment criteria also illustrates. Another factor is the strength of incentives that invite teachers to connect new knowledge resources to particular institutional purposes. Finally, the characteristics of the knowledge resources themselves are of importance, as they may be more or less scripted (Akrich, 1992). An implication is that teachers' interactions with knowledge resources, through activities like instructional planning or teacher collaboration, can be understood as sites where teachers' collective autonomy is shaped. As relationships between specific knowledge resources and competing institutional demands are constructed by teachers, they also position themselves 
and their instructional activities in relation to broader landscapes of educational reforms, epistemic infrastructures and the competing objectives inherent in educational practices.

\section{Discussion}

The truism that 'knowledge is power' takes on a specific expression in professional work, due to the role of knowledge as a source of public trust and legitimacy. Professionals' autonomy is dependent on this trust and legitimacy, and on their capacity to assess and define the knowledge that informs everyday work. This article has presented a three-part argument for how this aspect of autonomy is constructed and shaped at different planes of analysis through teachers' knowledge relations. The first part illustrated how a profession's knowledge culture and epistemic infrastructure shape practitioners' opportunities for taking collective responsibility for developing and safeguarding a professional knowledge base. The second part showed how different combinations of knowledge relations and organisational roles and routines at the school level can constitute teachers' collective autonomy, affording teachers contrasting opportunities to engage with new knowledge resources and to shape instructional development. The final part addressed how teachers' interactions with knowledge resources, and the ways in which these resources are connected to institutional demands and purposes, can shape the role of these resources within the practices of schooling. Through these processes, teachers also define their own roles in educational activities, for example by shaping the division of labour between teachers and students or allowing for expansive or restrictive learning processes in the classroom.

These interrelationships between knowledge practices and collective autonomy highlight the need for analytical attention to the material dimensions of knowledge resources, both in terms of specific resources and of the broader epistemic infrastructures that they are part of. Assessment criteria, curriculum documents, digital platforms for knowledge sharing and support structures for the recontextualisation of knowledge are all examples of artefacts 
that invite teachers to engage with knowledge in particular ways, based on their material and conceptual affordances and constraints. These constraints and affordances may to a considerable extent shape how teachers approach knowledge resources, but they may also be transgressed and transformed as teachers purposefully rework them (Edwards, 2017). Different interactional patterns with specific knowledge resources are interesting units of analysis in this respect. In many ways, this is what has occupied much literature on educational reform and instructional change. However, examining such processes as knowledge practices rather than implementation processes would shed light on how the characteristics of a profession' knowledge culture and epistemic infrastructure both inform, and is reshaped by, efforts aimed at educational change. It also allows us to investigate the formative role of knowledge on teachers' collective autonomy. Certain artefacts appear as particular dynamic in this respect, such as assessment criteria. In the research literature, assessment criteria occupy a range of positions, from significantly enhancing student learning (e.g. Black and Wiliam, 2009) to playing a key role in promoting instrumentalism and 'teaching to the test' (e.g. Torrance, 2007). Several of these findings occur within similar policy environments, which invite the question of how other mediating factors shape teachers' approaches to specific knowledge resources. Another key question is how teachers' work is positioned through these processes, for example, as 'instrumentalist coaches' (Torrance, 2007) or as teachers who can support students to engage in autonomous, deep learning.

From a cultural historical perspective, teachers' knowledge relations cannot be understood neither as purely individual attributes nor merely as a result of systemic properties. A question in need of further analysis is how the interrelationship between teachers' interactions with knowledge resources and institutional demands and purposes is realised in different empirical contexts. Variance between the following two factors would be 
particularly interesting to explore: settings where teachers have a more or less developed profession specific infrastructure, and settings where this infrastructure is orchestrated by different constellations of actors, such as policy makers, researchers, teacher associations, knowledge clearing houses and educational consultants. The Norwegian case can be viewed as an example where the lack of infrastructure has affected teachers' opportunities for engaging in continuous learning and the systematic development of a shared knowledge base. This is also visible in Norwegian teachers' calls for the state to provide them with more support structures for everyday work, for example in developing assessment criteria or conducting formative assessment (Hopfenbeck, Tolo, Florez \& El Masri, 2013; Mausethagen \& Mølstad, 2015). In contrast, the English context may represent a situation where teachers have been introduced to a very tightly scripted infrastructure, which has to a great extent been defined by policy makers without sufficient support from the profession (Beck, 2009; Day \& Smethem, 2009). In such situations, the epistemic infrastructure may be so tightly construed that processes of exploration and stabilisation of knowledge resources are stymied and where spaces for working agentically with knowledge resources are scarce. In both cases, an epistemic infrastructure collectively developed by the professions themselves is notably absent. Also in both cases, the characteristics of the professions' epistemic infrastructure affect teachers' abilities to autonomously define their collective knowledge base, but for quite different reasons. Navigating contemporary knowledge landscapes and policy environments is a formidable task, even in settings where a supportive infrastructure for assessing and recontextualising knowledge is provided. The more general question is how the combination of professional knowledge cultures and epistemic infrastructures produce affordances and constraints for teachers' capacities to collectively define the basis for professional work.

The final point is that the application of this analytical perspective invites a reconsideration of how professional autonomy is conceptualised. Historically, professional 
autonomy in the teaching profession has typically been associated with a high degree of individual discretion (Clement \& Vandenberghe, 2000; Little, 1990). However, this understanding of professional autonomy is currently being challenged (Frostenson, 2015; Mausethagen \& Mølstad, 2015). Two of the empirical examples (Sections 4.1 and 4.2) highlight that a one-sided emphasis on individual notions of autonomy may weaken teachers' collective capacity to define the direction of instructional development and the characteristics of the profession's knowledge base. In contemporary societies, characterised by their complex knowledge landscapes, we need a notion of professional autonomy that points not only to the individual exercise of discretion, but also to the extent to which professionals can collectively define what kinds of knowledge resources should be used towards which purposes and how. The latter is particularly pertinent given that actors, such as policy makers, educational consultants and knowledge clearinghouses, often play important roles in introducing new knowledge resources to schools. These resources are frequently embedded with conflicting motives, as they are designed to be used both as tools to support student learning and for purposes of accountability, such as data about student achievement (Coburn \& Turner, 2011; Mausethagen, 2013). More generally, notions of professional autonomy and responsibility are increasingly contested and mobilised to position professionals in particular ways, both by professionals and by outside actors (Evetts, 2009; Mausethagen \& Granlund, 2012; Noordegraaf, 2013). These developments call for conceptualisations of professional autonomy that go beyond the individual and can account for the profession's collective capacity to define the parameters of its work and the knowledge that informs its practices. It also invites professional organisations, who may historically have focused on topics such as pay and working hours, to involve themselves more systematically in constructing profession specific infrastructures “from within” (Evetts, 2003).

\section{Concluding comments}


This article has provided an initial account of the relationship between teachers' knowledge relations and the profession's collective autonomy. As outlined above, future research could benefit from examining the empirical manifestations of these relationships in more detail, with particular attention given to processes that afford and constrain these relationships, and to factors that serve to shape notions of collective autonomy as either a 'threat' or a 'promise'. For a profession that has endured much criticism and negative media attention (e.g., Elstad, 2009) over the past decades, exploring how to foster a constructive relationship between professional knowledge, autonomy and legitimacy through more systematic approaches to developing and safeguarding knowledge may also help teachers regain their status as trusted and valued professionals who responsibly engage with their societal mandate. 


\section{References}

Abbott, A. (1988). The system of professions: An essay on the division of expert labor. Chicago: University of Chicago Press.

Akrich, M. (1992). The de-scription of technical objects. In Bijker, W. \& Law, J. (eds.). Shaping Technology/ Building Society. Cambridge and London: MIT Press.

Bakkenes, I., Vermunt, J. D., \& Wubbels, T. (2010). Teacher learning in the context of educational innovation: Learning activities and learning outcomes of experienced teachers. Learning and Instruction, 20(6), 533-548.

Bathmaker, A. M. (2000). Standardising teaching: The introduction of the national standards for teaching and supporting learning in further education in England and Wales. Journal of InService Education, 26(1), 9-23.

Beck, J. (2008). Governmental professionalism: Re-professionalising or de-professionalising teachers in England? British Journal of Educational Studies, 56(2), 119-143.

Beck, J. (2009). Appropriating professionalism: Restructuring the official knowledge base of England's 'modernised' teaching profession. British Journal of Sociology of Education, 30(1), 3-14.

Biesta, G. (2004). Education, accountability, and the ethical demand: Can the democratic potential of accountability be regained?. Educational Theory 54(3), 233-250.

Biesta, G. (2007): Why "what works" won't work: Evidence-based practice and the democratic deficit in educational research. Educational Theory 57(1), 1-22.

Black, P., \& Wiliam, D. (1998). Assessment and classroom learning. Assessment in Education: Principles, Policy \& Practice, 5(1), 7-74.

Black, P., \& Wiliam, D. (2009). Developing the theory of formative assessment. Educational Assessment, Evaluation and Accountability, 21(1), 5-31.

Ceulemans, C., Simons, M., \& Struyf, E. (2012). Professional standards for teachers: How do they 'work'? An experiment in tracing standardisation in-the-making in teacher education. Pedagogy, Culture \& Society, 20(1), 29-47.

Clement, M., \& Vandenberghe, R. (2000). Teachers' professional development: A solitary or collegial (ad)venture? Teaching and Teacher Education, 16(1), 81-101.

Coburn, C. E. (2006). Framing the problem of reading instruction: Using frame analysis to uncover the microprocesses of policy implementation. American Educational Research Journal, 43(3), 343-349.

Coburn, C. E., \& Turner, E. O. (2012). The practice of data use: An introduction. American Journal of Education, 118(2), 99-111.

Cole, M. (1996). Cultural psychology: A once and future discipline. Cambridge, MA: The Belknap Press of Harvard University Press.

Cribb, A., \& Gewirtz, S. (2007). Unpacking autonomy and control in education: some conceptual and normative groundwork for a comparative analysis. European Educational Research Journal, 6(3), 203-213.

Day, C. (2002): School reform and transitions in teacher professionalism and identity. International Journal of Educational Research, 37(8), 677-692.

Day, C., \& Smethem, L. (2009). The effects of reform: Have teachers really lost their sense of professionalism? Journal of Educational Change, 10(2-3), 141-157. 
Preprint version of article published in Teaching and Teacher Education: An International Journal of Research and Studies. 65, 1-9. doi:10.1016/j.tate.2017.03.003. There may be minor differences between this manuscript and the published version.

Edwards, A., \& Daniels, H. (2012). The knowledge that matters in professional practices. Journal of Education and Work, 25(1), 39-58.

Edwards, A. (2008). Activity theory and small-scale interventions in schools. Journal of Educational Change, 9(4), 375-378.

Edwards, A. (forthcoming, 2017). The dialectic of person and practice: How cultural-historical accounts of agency can inform teacher education. In Clandinin, J. \& Husu, J. (eds.) Handbook on Research on Teacher Education. London: Sage.

Elstad, E. (2009). Schools which are named, shamed and blamed by the media: School accountability in Norway. Educational Assessment, Evaluation and Accountability, 21(2), 173-189.

Evans, L. (2011). The 'shape' of teacher professionalism in England: Professional standards, performance management, professional development and the changes proposed in the 2010 white paper. British Educational Research Journal, 37(5), 851-870.

Evetts, J. (2003): The sociological analysis of professionalism. Occupational change in the modern world. International Sociology 18(2), 395-415-

Evetts, J. (2009). New professionalism and new public management: Changes, continuities and consequences. Comparative Sociology, 8(2), 247-266.

Frostenson, M. (2015). Three forms of professional autonomy: De-professionalisation of teachers in a new light. Nordic Journal of Studies in Educational Policy, 1(2).

Gherardi, S. (2000). Practice-based theorizing on learning and knowing in organizations. Organization, 7(2), 211-223.

Gherardi, S. (2006). Organizational knowledge: The texture of workplace learning. Malden, MA: Blackwell Publishing.

Gherardi, S. (2009). Knowing and learning in practice-based studies: An introduction. Learning Organization, 16(5), 352-359.

Guile, D. (2010). The learning challenge of the knowledge economy. Rotterdam, the Netherlands: Sense Publishers.

Hargreaves, A. (1996). Teaching as a research-based profession: Possibilities and prospects. Paper presented at The Teacher Training Agency, London.

Hay, P. J., \& Macdonald, D. (2008). (Mis)appropriations of criteria and standards-referenced assessment in a performance-based subject. Assessment in Education: Principles, Policy \& Practice, 15(2), 153-168.

Hermansen, H. (2014). Recontextualising assessment resources for use in local settings: Opening up the black box of teachers' knowledge work. The Curriculum Journal, 25(4), 470-494.

Hermansen, H. (2015a). Knowledge work in the teaching profession: Opening up the black box of teachers' engagement with Assessment for Learning (Doctoral thesis). Norway: University of Oslo.

Hermansen, H. (2015b). Teachers' knowledge work in collective practice development: Approaches to introducing assessment for learning at the school level. Scandinavian Journal of Educational Research, 1-15. http://dx.doi.org/10.1080/ 00313831.2015.1066433.

Hermansen, H., \& Nerland, M. (2014). Reworking practice through an AfL project: An analysis of teachers' collaborative engagement with new assessment guidelines. British Educational Research Journal, 40(1), 187-206.

An analysis of teachers' collaborative engagement with new assessment guidelines. British Educational Research Journal, 40(1), 187e206.Hopfenbeck, T., Throndsen, I., Lie, S., \& Dale, E. L. (2012). Assessment with distinctly defined criteria: A research study of a national project. 
Policy Futures in Education, 10(4), 421-433.

Hopfenbeck, T., Tolo, A., Florez, T., \& El Masri, Y. (2013). Balancing Trust and Accountability? The Assessment for Learning Programme in Norway. OECD Education Working Papers no. 97.

Hopmann, S. (2007). Restrained Teaching: the common core of Didaktik. European Educational Research Journal, 6(2), 109-124.

Horn, I. S., \& Little, J. W. (2010). Attending to problems of practice: Routines and resources for professional learning in teachers' workplace interactions. American Educational Research Journal, 47(1), 181-217.

Hutchinson, C., \& Hayward, L. (2005). The journey so far: Assessment for learning in Scotland. The Curriculum Journal, 16(2), 225-248.

Jensen, K., Lahn, L., \& Nerland, M. (2012a). Professional learning in the knowledge society. Rotterdam, the Netherlands: Sense Publishers.

Jensen, K., Lahn, L., \& Nerland, M. (2012b). Professional learning in new knowledge landscapes: A cultural perspective. In Jensen, K., Lahn, L., \& Nerland, M. (eds.). Professional learning in the knowledge society. Rotterdam, the Netherlands: Sense Publishers.

Jensen, K., \& Christiansen, B. (2012). New patterns for epistemic engagement in nursing. In K. Jensen, L. Lahn \& M. Nerland (Eds.), Professional learning in the knowledge society (pp. 211-228). Rotterdam, The Netherlands: Sense Publishers.

Klenowski, V., \& Wyatt-Smith, C. (2012). The impact of high-stakes testing: The Australian Story. Assessment in Education: Principles, Policy \& Practice 19(1), 65-79.

Klette, K., \& Carlsten, T. C. (2012). Knowledge in teacher learning. In K. Jensen, L. C. Lahn \& M. Nerland (Eds.), Professional learning in the knowledge society (pp. 69-84). Rotterdam, the Netherlands: Sense Publishers.

Kleinhenz, E., \& Ingvarson, I. (2004). Teacher accountability in Australia: current policies and practices and their relation to the improvement of teaching and learning. Research Papers in Education, 19(1), 31-49.

Knorr Cetina, K. (1999). Epistemic cultures: How the sciences make knowledge. Cambridge, MA: Harvard University Press.

Knorr Cetina, K. (2001). Objectual practice. In Schatzki, T., Knorr Cetina, K. \& Savigny, E. v. (Eds.), The practice turn in contemporary theory. London: Routledge

Linell, P. (1998). Approaching dialogue: Talk, interaction and contexts in dialogical perspective. Amsterdam: John Benjamins.

Little, J. W. (1990). The persistence of privacy: Autonomy and initiative in teachers' professional relations. Teachers College Record, 91(4), 509-536.

Little, J. W. (2012). Understanding data use practice among teachers: The contribution of microprocess studies. American Journal of Education, 118(2), 143-166.

Lohman, M. C., \& Woolf, N. H. (2001). Self-initiated learning activities of experienced public school teachers: Methods, sources, and relevant organizational influences. Teachers and Teaching: Theory and Practice, 7(1), 59-74.

Lortie, D. C. (2002 [1975]). Schoolteacher: A sociological study. Chicago: University of Chicago Press.

Marshall, B., \& Drummond, M. J. (2006). How teachers engage with assessment for learning: Lessons from the classroom. Research Papers in Education, 21(2), 133-149. 
Mausethagen, S. (2013). Accountable for what and to whom? Changing representations and new legitimation discourses among teachers under increased external control. Journal of Educational Change, 14(4), 423-444.

Mausethagen, S., \& Granlund, L. (2012). Contested discourses of teacher professionalism: Current tensions between education policy and teachers' union. Journal of Education Policy, 27(6), $815-833$.

Mausethagen, S., \& Mølstad, C. E. (2015). Shifts in curriculum control: Contesting ideas of teacher autonomy. Nordic Journal of Studies in Educational Policy, 1(2), 30-41.

Mausethagen, S., \& Smeby, J. C. (2016). Contemporary education policy and teacher professionalism. In Dent, M., Bourgeault, I. L., Denis, J-L. \& Kuhlmann, E. (eds).: The Routledge Companion to the Professions and Professionalism (pp. 329-342). London and New York: Routledge.

Meirink, J., Meijer, P., Verloop, N., \& Bergen, T. C. (2009). How do teachers learn in the workplace? An examination of teacher learning activities. European Journal of Teacher Education, 32(3), 209-224.

Miettinen, R., Samra-Fredericks, D., \& Yanow, D. (2009). Re-turn to practice: An introductory essay. Organization Studies, 30(12), 1309-1327.

Nerland, M. (2008). Knowledge cultures and the shaping of work-based learning: The case of computer engineering. Vocations and Learning: Studies in Professional and Vocational Education, 1(1), 49-69.

Nerland, M. (2012). Professions as knowledge cultures. In K. Jensen, L. Lahn \& M. Nerland (Eds.), Professional learning in the knowledge society (pp. 27-48). Rotterdam, the Netherlands: Sense Publishers.

Nerland, M., \& Jensen, K. (2010). Objectual practice and learning in professional work. In S. Billett (Ed.), Learning through practice: Models, traditions, orientations and approaches (pp. 82103). Dordrecht, the Netherlands: Springer.

Nerland, M., \& Jensen, K. (2012): Epistemic practices and object relations in professional work. Journal of Education and Work, 25:1, 101-120.

Nerland, M., \& Karseth, B. (2013). The knowledge work of professional associations: Approaches to standardisation and forms of legitimisation. Journal of Education and Work, 28(1), 1-23

Nerland, M., \& Karseth, B. (2014). Standardization of professional knowledge and practice. In World Yearbook of Education. Oxon: Routledge.

Nicolini, D., Yanow, D., \& Gherardi, S. (2003). Knowing in organizations: A practice-based approach. Armonk, NY: M.E. Sharpe.

Noordegraaf, M. (2013). Reconfiguring professional work: Changing forms of professionalism in public services. Administration \& Society. doi: 10.1177/0095399713509242. 1-28.

Pedder, D., \& Opfer, V. D. (2013). Professional learning orientations: Patterns of dissonance and alignment between teachers' values and practices. Research Papers in Education, 28(5), 539570.

Richter, D., Kunter, M., Klusmann, U., Lüdtke, O., \& Baumert, J. (2011). Professional development across the teaching career: Teachers' uptake of formal and informal learning opportunities. Teaching and Teacher Education, 27(1), 116-126.

Sachs, J. (2003). Teacher professional standards: Controlling or developing teaching? Teachers and Teaching, 9(2), 175-186.

Sadler, D. R. (2007). Perils in the meticulous specification of goals and assessment criteria. Assessment in Education, 14(3), 387-392. 
Slavin, R. (2007). Evidence-based reform in education: What will it take? Paper presented at the European Conference on Educational Research, Ghent, Belgium.

Spicer, E. D. H. (2011). From artefact to tool: The development of teachers' collective agency in the enactment of reform. Pedagogies: An International Journal, 6(4), 359-380.

Stobart, G., \& Eggen, T. (2012). High-stakes testing: Value, fairness and consequences. Assessment in Education: Principles, Policy \& Practice, 19(1), 1-6.

Torrance, H. (2007). Assessment as learning? How the use of explicit learning objectives, assessment criteria and feedback in post-secondary education and training can come to dominate learning. Assessment in Education: Principles, Policy \& Practice, 14(3), 281-294.

Valli, L., \& Buese, D. (2007). The changing roles of teachers in an era of high-stakes accountability. American Educational Research Journal, 44(3), 519-558.

Van der Schaaf, M., Baartman, L., \& Prins, F. (2011). Exploring the role of assessment criteria during teachers' collaborative judgement processes of students' portfolios. Assessment \& Evaluation in Higher Education, 37(7), 847-860.

Vygotsky, L. S. (1978). Mind in society: The development of higher psychological processes. Cambridge, MA: Harvard University Press.

Wermke, W., \& Höstfält, G. (2014). Contextualizing teacher autonomy in time and space: A model for comparing various forms of governing the teaching profession. Journal of Curriculum Studies, 46(1), 58-80.

Wertsch, J. V. (1991). Voices of the mind: A sociocultural approach to mediated action. Cambridge, MA: Harvard University Press.

Wyatt-Smith, C., \& Klenowski, V. (2013). Explicit, latent and meta-criteria: types of criteria at play in professional judgement practice. Assessment in Education: Principles, Policy \& Practice, $20(1), 35-52$ 